\title{
Secondary Teacher Interacting with Materials Professors Strikes Gold James Ringlein
}

As a secondary school teacher interested in introducing materials science to my students, I have been given the opportunity to work with two outstanding professors who served as my mentors. This work, over the past seven summers, has led to innovative teaching approaches, published articles, and presentations at science museums and university seminars.

\section{Introduction to Materials Research I: Modeling of High School Physics}

Mark Robbins is a professor of physics at the Johns Hopkins University (JHU) and served as my first mentor during the summer of 2000, introducing me to the world of research-quality simulations. I spent eight weeks with Mark and his graduate students modeling gaseous systems and the frictional characteristics between two surfaces sliding across each other. At the outset, I used the same software that Mark's group used to investigate the degree of fit a gas system exhibited in relation to the van der Waals equation of state. I also gained an understanding of frictional forces and their atomic origins from simulation work.

These experiments led me to propose modeling similar systems using software I was already familiar with, namely Interactive Physics ${ }^{\mathrm{TM}}$. The idea was to create simulations that would illustrate the physics exhibited in these research quality programs while making the end result accessible to high school and college level teachers and students. This work was our focus over the next four summers, culminating in three published articles, the first two in specific publications for teachers. In The Science Teacher (September 2003), my article "The Tablecloth Trick: Take II," focused on the often misunderstood application of friction to the famous magic trick and physics demonstration. My second article, "Interactive Instruction on Ideal and Real Gases," published in The Physics Teacher (February 2004), focused on the process of teaching students about the assumptions of the ideal gas law and the behavior of real gases with a series of simple simulations. Later that year, Mark and I co-authored an article for the American Journal of Physics (July 2004), "Understanding and Illustrating the Atomic Origins of Friction," which combined a lucid explanation of modern friction principles with simulations that illustrate each point.

This introduction to materials research prepared me for a later experience in which I was ready to invite some of my acid in dealloying. students to join me in a new research project with collaborators at a local college.

\section{Introduction to Materials Research II: Experimental Studies of Nanoporous Gold}

Beginning in the summer of 2005, I worked in the laboratory of Jonah Erlebacher, professor of materials science and engineering at JHU. Our goal was to develop my knowledge of nanoporous gold (NPG) and possibly develop educational applications for the high school classroom based on the experience.

We spent the majority of the first twoweek session learning how to create, handle, and analyze the performance of NPG, with an eye toward improving the efficiency of hydrogen fuel cells. I began by learning how to handle a 12 carat gold leaf.

Gold leaf is very thin, very fragile, and is typically purchased in books containing 25 square sheets $(\sim 8.6 \mathrm{~cm})$ separated by thin paper. Trying to handle the leaf with one's fingers is a lesson in frustration. I found out quickly why the JHU researchers had developed a special technique for handling the 100-nm thick leaf. In Jonah's laboratory, we manipulated the leaf with a patented graphite roller which (when appropriately damp) rolled the leaf nicely out of its book, allowing it to be placed directly into a pan filled with deionized water. Because of surface tension and some air trapped beneath the leaf, the thin film of 12 carat gold floats on the water (see Figure 1). When one is ready to make nanoporous gold, the leaf is then picked up out of the water by the graphite roller and placed into a nitric acid solution used to remove the silver. Twelve-carat-gold

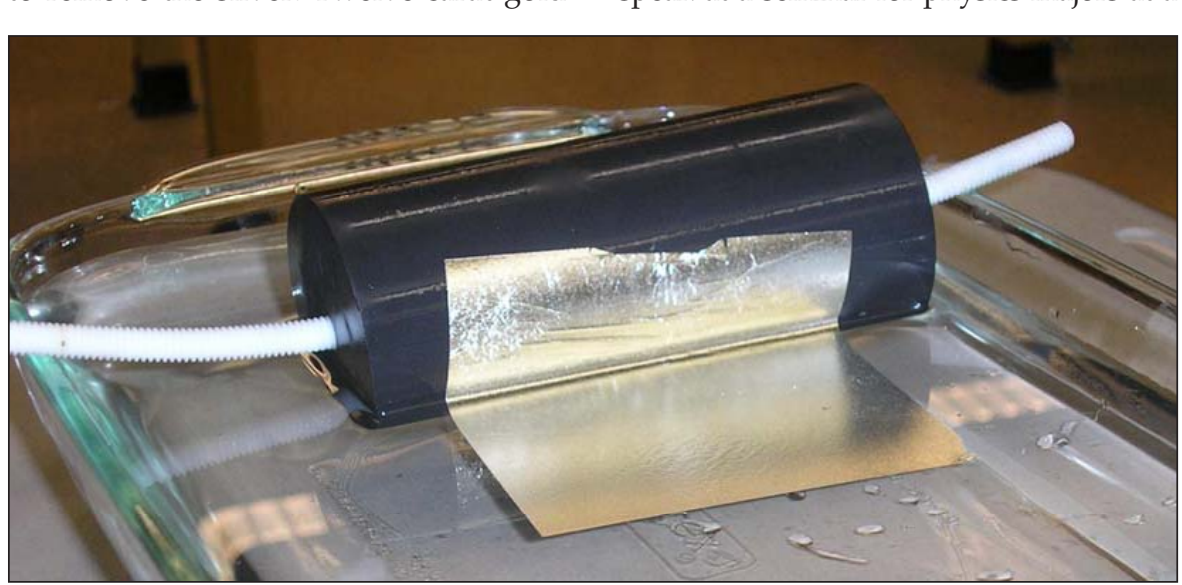

Figure 1. Gold leaf floating on water and being lifted by a graphite roller. The threaded rods supporting the sides are unreactive Teflon. These are used because of exposure to nitric the silver is removed, the remaining NPG is about $30-40 \mathrm{~nm}$ thick. The amazing fact is that the gold restructures itself into a fairly uniform porosity as the silver is removed.

Our emphasis that summer was on developing the capabilities of NPG to enhance the performance of hydrogen fuel cells. By making them even more efficient, researchers hope to increase their cost-effectiveness in alternatives to the current fossil fuel infrastructure.

We plated the NPG with platinum in a cleverly designed deposition process that again utilized the floating property of the NPG. Once coated with an atomically thin layer of platinum, the NPG was placed on both sides of a proton exchange membrane to complete the fuel cell. Much of the remainder of the twoweek session was spent testing these NPG-based hydrogen fuel cells for their energy conversion capabilities. These activities enhanced my knowledge of hydrogen fuel cells, which directly benefits my students. I had already used fuel cell cars with my physics students in order to summarize a variety of physics principles at the end of the school year. My experience at JHU added depth and credibility to my lessons on hydrogen fuel cell car performance.

\section{Involving Students in the Research}

Upon my return to school that fall, our school public relations agent offered my summer research story to local media and one newspaper published an interview. The media attention led to an invitation to speak at a seminar for physics majors at a leaf is $50 \%$ gold by weight, and when all 
local university-Millersville-at which I met Natalia Dushkina, a professor of physics who was testing thin films at Millersville University with a technique called surface plasmon resonance. She invited me to bring students and NPG samples to her laboratory, and we scheduled a visit for April 2006. I recruited three interested students to make NPG with me in our school chemistry laboratory. We varied the concentration of the nitric acid used and the time for the gold leaf to remain in solution. After dealloying, we lifted the NPG on glass microscope slides. After it dries, the gold adheres reasonably well to the untreated glass; see Figure 2. We brought a collection of NPG-coated glass slides with us to Millersville University (MU) that April, not really knowing what to expect.

Natalia has been exploring the possibilities of using surface plasmon resonance as a means of sensing the presence of thin films of biomaterials. The effect can be seen using apparatus that is fairly simple in principle, though the highly refined measurements require a great deal of care and expertise. The idea is that polarized laser light passing through a glass prism can be internally reflected and exit the prism in a specific direction.

The intensity of the light as it emerges from the prism can be dramatically affected by the presence of thin films $(\sim 40 \mathrm{~nm})$ on the back side of the prism where the internal reflection occurs (see Figure 3 ). Specifically, the intensity of the emergent light at particular angles drops off dramatically depending on the nature of the thin film. So a thin film of silver has a characteristic angle of intensity drop-off that is different from gold, and would be different from other materials.

I really did not understand the effect until two of Natalia's senior physics majors demonstrated it. The apparatus consisted of a polarized laser, a prism mounted for rotation (and sensitive angle measurement), a detector for reflected light intensity, and a multimeter providing a digital value for the intensity in terms of a current generated. After the NPG-coated slide was placed on the back of the prism, the laser was directed through it and internally reflected out the other face. In very fine rotational increments, Natalia's students turned the prism noting the output current based on the light level hitting the photodetector. Then our turn came. With my students manning the prism rotation and the data recording, I was left to ponder the possibilities. Would NPG act like other gold films? If it did work, could we set up a surface plasmon resonance system at our

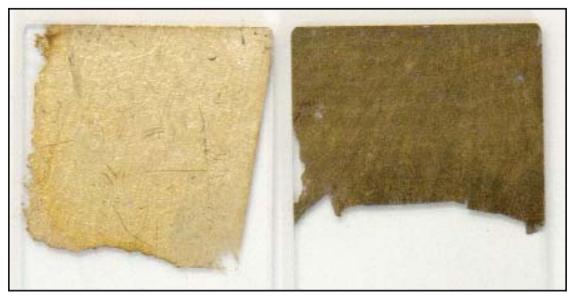

Figure 2. Nanoporous gold on glass microscope slides. Note the unusually dark copper color of the slide on the right, which had been dealloyed for a much longer time than the sample on the left.

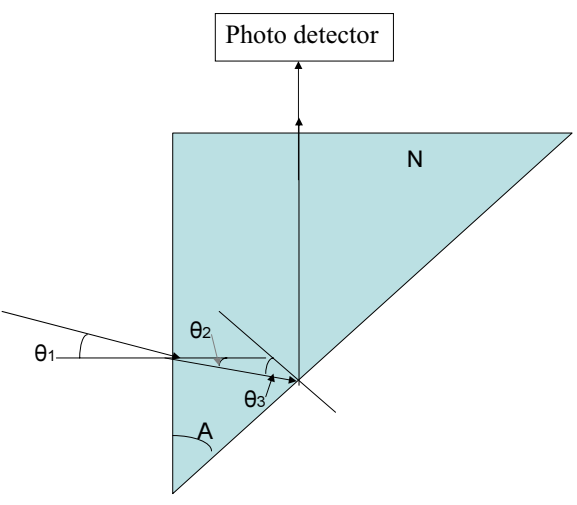

Figure 3. Surface plasmon resonance method in which incoming $\mathrm{He}-\mathrm{Ne}$ polarized laser beam is directed at the thin sample film which lies on the hypotenuse of the prism; $\theta_{1}$ is the angle of incidence for the laser as it enters the prism; $\theta_{2}$ is the refracted ray passing through the prism; and $\theta_{3}$ is the incident angle for the beam as it enters the thin nanoporous gold film on the hypotenuse of the prism. The gold is adhered to a microscope slide and a special oil is used between the prism and the slide which matches the indices of refraction of the prism and the glass slide. The photodetector is connected to a PC for data collection. Diagram by N. Dushkina, Millersville University.

own school? If that is not practical, could we continue to work with equipment periodically at Millersville University? The current values began to drop as we suspected they would. However, we never observed the steep drop-off truly characteristic of the effect. We left that day knowing that we had had some success, but disappointed that our results did not act as a thin gold film was supposed to. Still, the senior students wanted us to leave our slide behind because they thought perhaps a more careful analysis would reveal something we had missed. After all, we were rookies.
Our hopes were realized when we received an e-mail a few days later confirming that the university students, after performing a more precise and detailed characterization of our sample, had seen the steep drop-off in reflected light intensity at just the precise angle that gold should have had. The slides we had made proved to be useful to researchers at a local university in that they had not tested NPG before with their apparatus, and found results exactly as they had hoped. It was a collaborative success story between novice high school nonporous gold manufacturers and a local university using novel techniques for studying thin films.

In the fall of 2006, one of my senior students has taken on the task of creating a surface plasmon resonance testing apparatus in a defunct darkroom at my school as part of a science fair project related to the optical properties of nanoporous gold. We are hopeful of recreating the effect we saw that spring, and perhaps testing our own NPG films with it. Jonah from JHU gave a talk at my school in November that year, illustrating the historical uses of gold and the modern potential of this material as applied to nanotechnology.

The benefit of my collaborative work with the materials researchers at JHU continues to expand. This year we hope to develop our own high quality surface plasmon apparatus, and expand our collaboration with professors at Millersville University as well as JHU. Even my work with middle school students has been affected by the experience. Our First Lego League robotics challenge for 2006 is based on nanotechnology, and I feel very confident that I can coach our students to success in an area I have become familiar with through these collaborations.

\section{Acknowledgments}

Jonah Erlebacher's work is sponsored by the Department of Energy's Hydrogen Fuel Initiative. More information on Natalia Dushkina's apparatus can be found on the Millersville University Web site http:/ / muweb.millersville.edu/ $\sim$ physics/exp.of.the.month/87/ (accessed January 2007).

James Ringlein is an instructor of physics and physical science at Lancaster Country Day School in Lancaster, Pa. Since 2000, he has participated in the educational outreach program of the Johns Hopkins University Materials Research Science and Engineering Center supported by the National Science Foundation. 